\title{
RANCANG BANGUN SISTEM PEMBERIAN PAKAN AYAM BROILER BERBASIS MIKROKONTROLLER
}

\author{
Ainul Farichah ${ }^{1}$, Aditya Akbar Riadi ${ }^{2}$, Alif Catur Murti ${ }^{3}$ \\ ${ }^{1}$ Program Studi Teknik Informatika, Fakultas Teknik, Universitas Muria Kudus, Jl. Lingkar Utara \\ UMK, Gondangmanis, Bae, Kudus, 59327 \\ E-mail: 201651146@umk.ac.id, aditya.akbar@umk.ac.id, alif.catur@umk.ac.id
}

\section{ARTICLE INFO}

Article history:

Received 26 July 2021

Received in revised form 3 August 2021

Accepted 13 August 2021

Available online 18 August 2021

\begin{abstract}
Broiler Chicken Feed System is a tool that is implemented using microcontroller technology. The focus of technology in industry 4.0 is that all devices can be controlled and monitored remotely, as long as they are connected to a network. In accordance with this vision, this technology makes it easier for farmers to feed chickens that were originally still using manual labor, then made automatically by implementing microcontroller technology consisting of SIM800L, Arduino, servo motors, and ultrasonic sensors. By using two ultrasonic sensors that are placed to enter orders and provide information about the stock of chicken feed this technology can work well. The focus of this technology is that it can be used for remote monitoring. Not only that, this technology can also send notifications to the farmer's smartphone to show the condition of the chicken feed stock that is still available. By applying this technology, chicken farmers can combine and feed their chickens from anywhere.
\end{abstract}

Keywords: Broiler Chicken Feeding System, Monitoring, Industy 4.0, Microcontroller.

\section{PENDAHULUAN}

Produk Domestik Bruto (PDB) dalah merupakan jumlah nilai tambah yang dihasilkan seluruh unit usaha dalam suatu negara tertentu, atau merupakan jumlah nilai barang dan jasa akhir yang dihasilkan oleh seluruh unit ekonomi. Berdasarkan data Badan Pusat Statistik Republik Indonesia (BPS RI), PDB atas harga konstan Subsektor Peternakan tahun 2020 (Angka Sangat Sementara) sebesar Rp 167.084,8 Milyar atau mengalami penurunan sebesar 0,33\% dibandingkan tahun 2019* (Angka Sementara). Subsektor Peternakan mengalami perubahan yang disebabkan menurunnya permintaan industri pemotongan hewan (penurunan produksi daging ayam ras broiler dan daging sapi/kerbau) sebagai dampak pandemi COVID-19.[1]

Dalam hukum supplay and demand, berkembangnya industri peternakan termasuk ternak ayam ras di Indonesia menyebabkan permintaan terhadap pakan terus meningkat secara signifikan. Pakan merupakan input utama dalam produksi daging ayam. Dalam segi perhitungan biaya produksi daging, $70 \%$ biaya adalah pakan, sedangkan yang lain mengenai bibit dan buaya perawatan hanya menempati sisa 30\%nya. Sehingga dapat dilihat begitu besarnya peranan pakan dalam produksi daging ayam. [2] 
Pada umumnya para peternak ayam masih menggunakan sistem konvensional untuk memberi makan ayam-ayam yang dipelihara. Mereka masih menggunakan tangan untuk menaburkan pakan pada wadah pakan dan berjalan sepanjang kandang ayam yang sangat luas. Kegiatan seperti ini bagi peternak ayam sangatlah menyita waktu dan tenaga. Terlebih lagi dalam komposisi jumlah pakan yang akan diberikan dalam 1 waktu. Belum lagi ketika peternak ayam sedang ada kepentingan untuk keluar kota, sehingga butuh adanya orang pengganti untuk mengurus peternakannya. Pemberian pakan ayam adalah kegiatan yang rutin dan pasti dilakukan oleh peternak. Pemberian pakan ayam dapat dipermudah dengan penerapan teknologi otomasi.

Saat ini sistem otomasi sudah banyak diimplementasikan dalam berbagai bidang, salah satunya dalam bidang peternakan. Beberapa penelitian sebelumnya membahas tentang pengontrolan sistem otomasi pemberian pakan dan minum ayam menggunakan mikrokontroler tetapi tidak mengurangi kualitas dari ayam itu sendiri.[3]-[5] Penerapan teknologi ini menghasilkan peningkatan efisiensi yang cukup signifikan dalam penggunaan pakan tanpa mengurangi bobot ternak pada saat panen dilakukan. Dari hasil penelitian juga alat ini dapat dikembangkan dengan menggunakan konveyor yang mana dapat memberikan pakan ternak secara otomatis, teratur, dan terjadwal sesuai dengan jumlah dan umur dari ternak.[3] Dalam penelitian ini nantinya disamping membuat sistem pakan secara otomatis, penelitian ini juga mempertimbangkan masalah stok dari pakan ayam yang ada, ketika stok pakan ayam sudah mencapai batas limit, sistem segera memberikan notifikasi berupa sms ke smartphone peternak.

\section{METODE}

\section{Observasi}

Melalui observasi atau pengamatan langsung ke lokasi peternakan ayam, untuk mengetahui proses perancangan sistem pemberian pakan ayam broiler berbasis mikrokontroller dengan memperhitungkan suatu bahan dan peralatan yang digunakan.

\section{Studi literatur}

Mengumpulkan data dengan cara membaca jurnal-jurnal yang terkait dengan pokok pembahasan ataupun referensi lain yang dapat dipergunakan.

\section{Tahapan perancangan sistem mengguakan metode Waterfall, sebagai berikut :}

a) Requirement Analisis

Peneliti melakukan analisis data dengan melakukan studi literatur dan wawancara dengan peternak ayam.

b) System Design

Berbasis dari hasil analisa, kemudian peneliti menyesuaikan kebutuhan sistem yang akan dibuat dengan kondisi riil dilapangan.

c) Implementation

Proses dilakukan secara bertahap dalam mengintegrasikan beberapa sensor dan kesesuaian teknis kerjanya.

d) Integration \& Testing

Dilakukan pengujian dengan menggunakan teknik blackbox.

e) Operation \& Maintenance

Pada tahap akhir, perlu dilakukan peremajaan dan perwatan terhadap komponen yang mudah rusak. Serta penyesuaian ketika terjadi error.

\section{PERANCANGAN SISTEM}

\section{a. Desain Rangkaian Sistem}

Adapun desain konsep dari sistem pemberian pakan ayam broiler yang akan dibangun seperti gambar 1 dibawah ini :

TRANSFORMATIKA Vol. 19, No. 1, July 2021: $95-101$ 


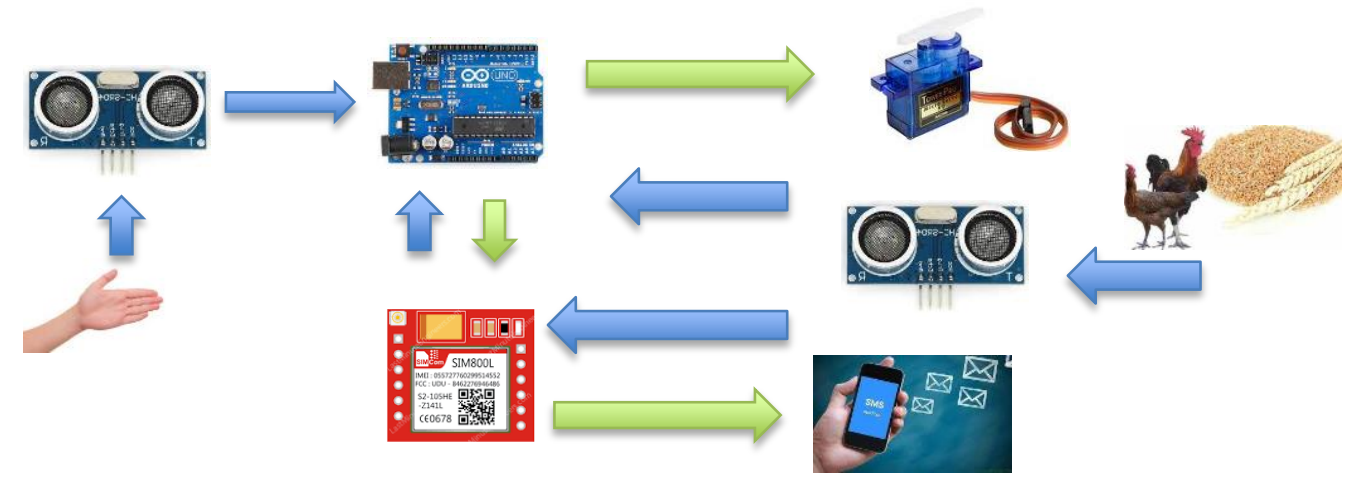

Gambar 1. Desain Konsep Implementasi Teknologi

Pada gambar 1 :

- Simbol arah bewarna biru adalah merupakan jalur input (perintah)

- Simbol arah bewarna hijau adalah merupakan jalur output ( aksi/informasi )

- Jalur Input 1.

Input berupa gerakan tangan, sensor ultrasonik mendeteksi gerakan tangan kemudian diteruskan ke microcontroller, input diterima kemudian motor servo memberikan aksi berupa membuka katup kotak pakan ayam (selama 5 detik).

Setelah selesai akan menutup kembali dan sensor ultrasonik yang berada pada kotak pakan akan mendeteksi dan memberikan input berupa kondis pakan ayam yang tersisa. Jika melebihi limit batas / kondisi pakan menipis makan akan meneruskan perintah ke microcontroller untuk mengirimkan notifikasi berupa sms ke smartphone peternak.

- Jalur input 2

Input berupa sms yang dikirimkan melalui smartphone pengguna untuk memberikan pakan. pesan diterima kemudian di proses oleh microcontroller, input diterima kemudian motor servo memberikan aksi berupa membuka katup kotak pakan ayam (selama 5 detik). Setelah selesai akan menutup kembali dan sensor ultrasonik yang berada pada kotak pakan akan mendeteksi dan memberikan input berupa kondis pakan ayam yang tersisa. Jika melebihi limit batas / kondisi pakan menipis makan akan meneruskan perintah ke microcontroller untuk mengirimkan notifikasi berupa sms ke smartphone peternak.

Untuk mengatasi kelalaian pengguna atau dalam hal ini adalah peternak, maka secara otomatis ada periode pemberian makan yang sudah diatur dan ditanamkan ke dalam microcontorller yaitu pada pagi dan sore hari. Desain pada katup penutup pakan ayam yang dikendalikan dengan motor servo mempengaruhi jumlah pakan yang akan keluar ketika terbuka selama 5 detik. Semakin besar katup, maka jumlah pakan yang keluar akan semakin banyak. Pada peneltian ini sudah disesuaikan dengan kebutuhan dari peternak.

\section{b. Flowchart}

Dalam sistem ini menggunakan 2 buah sensor ultrasonic, adapun flowchart cara kerja pada Sistem Pemberian Pakan Ayam Broiler Berbasis Mikrokontroller yang dibangun terlihat pada gambar 2 dan gambar 3 yaitu : 


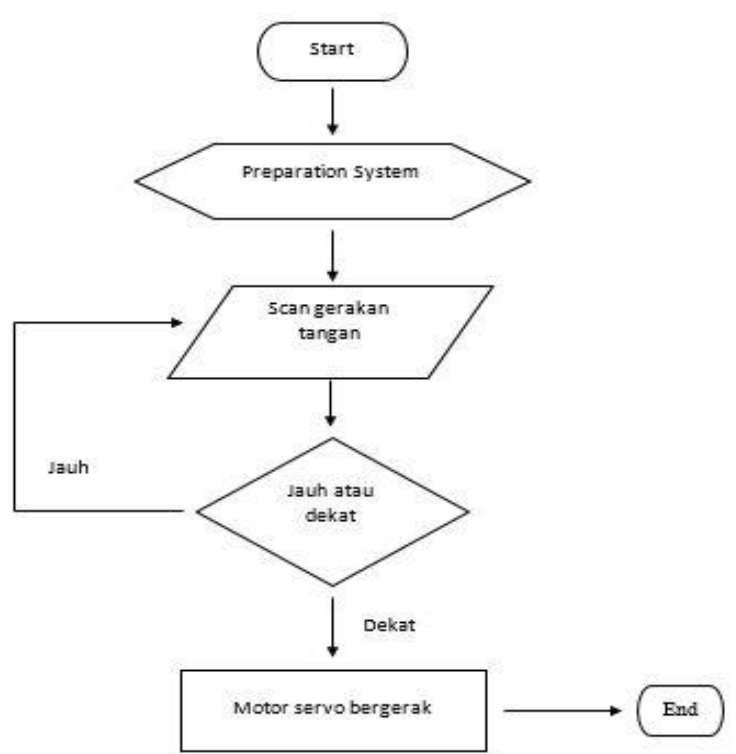

Gambar 2. Flowchart Kerja sensor ultrasonik pertama

Pada gambar 2 Sensor ultrasonik digunakan untuk mengecek input berupa gerakan tangan, Jika tidak terdeteksi (Jauh maka motor servo tidak akan bergerak) sedangkan apabila gerakan tangan terbaca (dekat) maka motor servo akan bergerak untuk membuka katup pakan ayam.

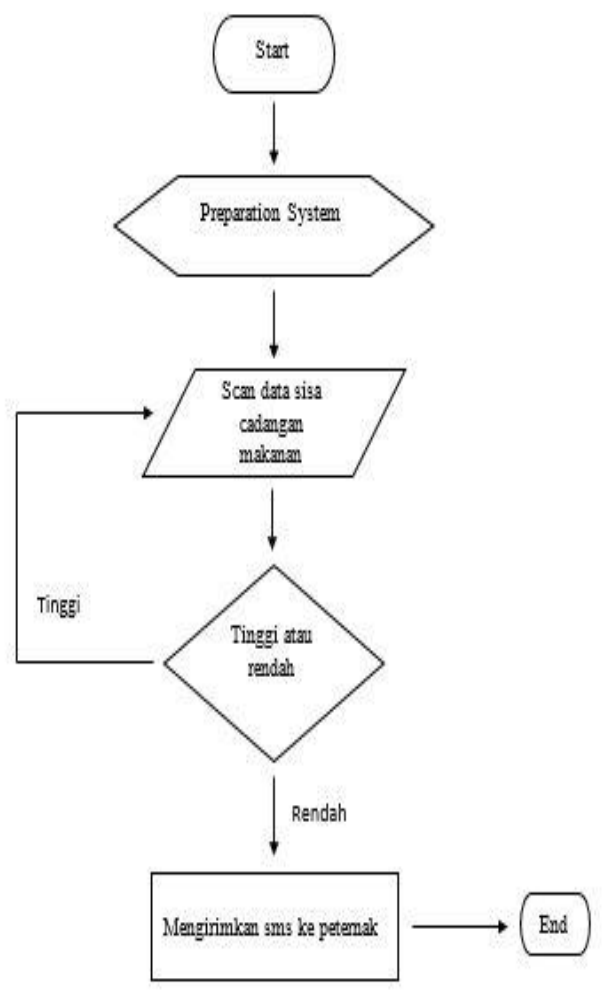

Gambar 3. Flowchart Kerja sensor ultrasonik kedua

TRANSFORMATIKA Vol. 19, No. 1, July 2021: 95 - 101 
Pada gambar 3 Sensor ultrasonik digunakan untuk mengecek input berupa jarak pakan ayam , ketika jarak masih dekat (tinggi) maka pakan ayam masih banyak, sedangkan jika jarak jauh (renda) maka akam mentriger untuk mengirimkan sms notifikasi pada smartphone peternak.

\section{HASIL DAN PEMBAHASAN}

a. Pengujian sensor ultrasonik 1

Pengujian sensor ultrasonik berfungsi untuk mendeteksi gerakan tangan yang di berikan oleh peternak sebagai intruksi. Pada pengujian ini dilakukan sebanyak 3 kali percobaan sensor dapat mendeteksi gerakan tangan secara baik. Berikut hasil percobaan sensor ultrasonik:

\begin{tabular}{|c|c|c|}
\hline No & Jarak percobaan & Terdeteksi \\
\hline 1 & $3 \mathrm{~cm}$ & Servo bergerak \\
\hline 2 & $5 \mathrm{~cm}$ & Servo bergerak \\
\hline 3 & $10 \mathrm{~cm}$ & Servo bergerak \\
\hline
\end{tabular}

Pada tabel 1 merupakan hasil percobaan Sensor ultrasonik sebanyak 3 kali percobaan dan sensor dapat mendeteksi gerakan tangan dengan baik, lebih dari itu maka servo tidak akan bergerak.

\section{b. Pengujian sensor ultrasonik 2}

Pengujian sensor ultrasonik berfungsi untuk mendeteksi jumlah pakan ayam. Pada pengujian ini dilakukan sebanyak 3 kali percobaan sensor dapat mendeteksi gerakan tangan secara baik. Berikut hasil percobaan sensor ultrasonik:

Tabel 2. Hasil Percobaan Sensor ultrasonic

\begin{tabular}{cccc}
\hline No & Jarak percobaan & Terdeteksi & $\begin{array}{c}\text { SIM800L } \\
\text { Mengirim } \\
\text { notifikasi }\end{array}$ \\
\hline 1 & $10 \mathrm{~cm}$ & Tinggi & Tidak \\
2 & $11 \mathrm{~cm}$ & Rendah & Mengirim \\
3 & $15 \mathrm{~cm}$ & Rendah & Mengirim \\
4 & $20 \mathrm{~cm}$ & Rendah & Mengirim \\
& & & Mengirim \\
\hline
\end{tabular}

Pada tabel 2 merupakan hasil percobaan Sensor ultrasonik sebanyak 4 kali percobaan dan sensor dapat mendeteksi kondisi pakan dengan baik, Jika melebihi jarak $10 \mathrm{~cm}$ maka akan pakan dianggap sudah mencapai stok yang sedikit. notifikasi berupa sms seluler dari sistem ke handphone pemilik (peternak) menggunakan modul GSM SIM800L. Telepon seluler ini untuk memberitahu pemilik bahwa keadaan pakan wadah utama telah habis dan harus segera diidi kembali. Dalam modul SIM GSM 800L yang perlu diperhatikan adalah dalam penggunaannya memerlukan catu daya dan Converter Step untuk menurunkan daya. Dikarenakan tegangan berasal dari Arduino Uno tidak cukup kuat untuk mengalirkan arus yang dibutuhkan pada modul GSM SIM800L. Gambar 3 menunjukkan notifikasi ketika pakan hampir/mau habis.

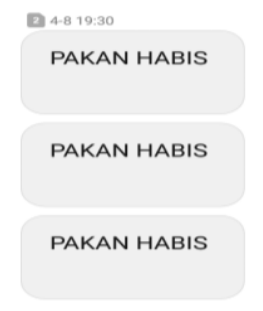

Gambar 4 Notifikasi yang diterima ketika pakan habis. 
Pada gambar 4 menunjukkan notifikasi telepon seluler dapat diterima oleh peternak, sehingga peternak dapat mengetahui kondisi wadah pakan utama telah habis dan harus diisi kembali.

\section{KESIMPULAN}

Berdasarkan hasil penelitian ini dapat disimpulkan bahwa :

a. Microcontroller dapat diimplementasikan pada teknologi pemberian pakan ayam.

b. Desain penggunaan 2 buah sensor ultrasonic dapat digunakan untuk mengetahui Gerakan tangan dan kondisi pakan ayam.

c. Sistem pembuka katup pakan ayam selama 5 detik sudah mampu untuk memberi pakan ayam. (dengan pertimbangan sudut katup dan besar katup penutup pakan ayam).

\section{DAFTAR PUSTAKA}

[1] D. J. P. dan K. H. K. P. Pertanian, "LAPORAN TAHUNAN 2020 DITJEN PKH,” Lap. Tah., 1967.

[2] K. KARIYASA and B. SINAGA, "Analisis Perilaku Pasar Pakan Dan Daging Ayam Ras Di Indonesia: Pendekatan Model Ekonomerika Simultan (Feed and Chicken Meat Markets Behavior Analysis in Indonesia: Simultaneous Econometric Model Approach))," SOCA Socioecon. Agric. Agribus., vol. 7, no. 2, 2007.

[3] G. Vinanda, H. Harianto, and L. Anggraeni, "Risiko Produksi Ayam Broiler Dan Preferensi Peternak Di Kabupaten Bekasi," J. Manaj. dan Agribisnis, vol. 13, no. 1, pp. 50-58, 2016, doi: 10.17358/jma.13.1.50.

[4] K. Setyadjit, T. Mujiono, and M. H. P, "Otomatisasi Pemberian Pakan Ayam Petelor Berbasis Fuzzy," vol. 2007, no. Snati, 2007.

[5] M. S. Son, "Pengembangan Mikrokontroler Sebagai Remote Control Berbasis Android," J. Tek. Inform., vol. 11, no. 1, pp. 67-74, 2018, doi: 10.15408/jti.v11i1.6293.

[6] S. Sutarsi, "Mikrokontroler dan Interface," pp. 2-3, 2017, [Online]. Available: https://scholar.google.co.id/scholar?hl=id\&as_sdt=0\%2C5\&q=jurnal+artikel+ilmiah\&btnG=.

[7] A. Ridhamuttaqin, A. Trisanto, and E. Nasrullah, "Rancang Bangun Model Sistem Pemberi Pakan Ayam Otomatis Berbasis Fuzzy Logic Control," Electrician, vol. 7, no. 3, pp. 125-137, 2013.

[8] E. D. Nawali, S. R. U. . Sompie, and N. M. Tulung, "Rancang Bangun Alat Penguras Dan Pengisi Tempat Minum Ternak Ayam Berbasis Mikrokontroler Atmega 16," E-Journal Tek. Elektro Dan Komput., vol. 4, no. 7, pp. 25-34, 2015.

[9] D. Kurnia and V. Widiasih, "Implementasi Nodemcu Dalam Prototipe Sistem Pemberian Pakan Ayam Otomatis Dan Presisi Berbasis Web," J. Teknol., vol. 11, no. 2, pp. 169-177, 2019, [Online]. Available: https://jurnal.umj.ac.id/index.php/jurtek/article/view/2838/3288.

TRANSFORMATIKA Vol. 19, No. 1, July 2021: 95-101 
[10] Anna Nur Nazilah Chamim, "PENGGUNAAN MICROCONTROLLER SEBAGAI PENDETEKSI POSISI DENGAN MENGGUNAKAN SINYAL GSM," JUNRNAL Inform. VOL 4 NO 1, vol. 4, no. 1, pp. 430-439, 2010.

[11] M. A. Zainudin, "Model Sistem Pemberi Pakan Pada Ternak Ayam Petelur Berbasis SMS Gateway,” Progresif J. Ilm. Komput., vol. 15, pp. 89-96, 2019, [Online]. Available: http://ojs.stmik-banjarbaru.ac.id/index.php/progresif/article/view/411.

[12] T. W. Wisjhnuadji and A. Narendro, "Dispenser Pakan Ternak Ayam Otomatis Berbasis Mikrokontroler Atmega 8535," pp. 25-30, 2017.

[13] K. D. Ariyanti, J. Jamaluddin, and M. Rais, "Modifikasi Alat Pemberi Pakan Ayam Otomatis Berbasis Mikrokontroler ATMEGA 3285.," J. Pendidik. Teknol. Pertan., vol. 5, no. 2, p. 73, 2020, doi: 10.26858/jptp.v5i2.9934.

[14] P. Roger S and M. Bruce R, Software engineering, vol. 9 ed, no. 9/10. 2019.

[15] Noviana Widyaningrum and Unan Yusmaniar Oktiawati, "Sistem Pemantauan dan Pengendalian Debit Fluida Berbasis Arduino dan Website," J. Nas. Tek. Elektro dan Teknol. Inf., vol. 9, no. 3, pp. 287-295, 2020, doi: 10.22146/.v9i3.261. 